\title{
Choosing a Professional: The Influence of Practitioner Nationality, Experience, and Sex in Shaping Preferences for Accountants
}

\author{
Adrian Furnham¹, Alastair McClelland ${ }^{2}$ \\ ${ }^{1}$ Norwegian Business School (BI), Nydalveien, Olso, Norway \\ ${ }^{2}$ Research Department of Experimental Psychology, University College London, London, UK \\ Email: a.furnham@ucl.ac.uk
}

How to cite this paper: Furnham, A., \& McClelland, A. (2019). Choosing a Professional: The Influence of Practitioner Nationality, Experience, and Sex in Shaping Preferences for Accountants. Psychology, 10, 1396-1405.

https://doi.org/10.4236/psych.2019.1010091

Received: June 2, 2019

Accepted: July 27, 2019

Published: July 30, 2019

Copyright $\odot 2019$ by author(s) and Scientific Research Publishing Inc. This work is licensed under the Creative Commons Attribution International License (CC BY 4.0).

http://creativecommons.org/licenses/by/4.0/

\begin{abstract}
The present study examined British adult participants preference for an accountant as a function of the latter's demographics and experience. A sample of British participants completed a questionnaire in which they were asked to rate eight accountants stratified by nationality (British versus Asian), sex (male versus female), and experience (great versus moderate). A mixed-design analysis of variance showed a preference for female accounts trained in the home country. There were also a number of significant two- and three-way interactions, although the effect sizes of these interactions were relatively small. These results are discussed in relation to the extant literature on patient preferences for different types of health care practitioners.
\end{abstract}

\section{Keywords}

Client Preferences, Accountants, Age, Gender, Nationality, Experience

\section{Introduction}

\section{Choosing an accountant}

This study concerns the sort of factors that potential clients take into account when choosing an accountant. It is one of a series of studies concerned with the choice of a professional like a doctor (Furnham, Petrides, \& Temple, 2006), a dentist (Furnham \& Swami, 2009; Swami, McClelland, Bedi, \& Furnham, 2011), a psychological counsellor (Furnham \& Swami, 2008) or a lawyer (Furnham, McClelland, \& Swami, 2012). The central question is after experience and expertise, what factors are relevant when a person comes to choose their personal, professional accountant. It is an extension of various other studies done on the 
choice of specific professionals.

The major interest has been in the medical field. Short (1993) suggested that patient impressions of their practitioners were formed fairly quickly and shaped the consultation process. Practitioner choice, as opposed to allocation is associated with greater patient satisfaction with the consultation, improved disclosure of information to the practitioner, and more positive patient-practitioner relationships (Derose, Hays, McCaffrey, \& Baker, 2001; Elstad, 1994; Young, 1979).

Much of the literature on patient preferences for practitioners has focused on a few demographic factors. There is a well-established finding for same-sex practitioners of general medical care (Ahmad, Hansa, Rawlins, \& Stewart, 2002; Derose et al., 2001; Elstad, 1994; Furnham, Petrides, \& Temple, 2006; Kapphahn, Wilson, \& Klein, 1999), particularly when patients present with intimate health concerns (e.g., Brink-Muinen, Bakker, \& Bensing, 1994; Kerssens, Bensing, \& Abdela, 1997; Plunkett, Kohlin, \& Milad, 2002). Female practitioners appear to be judged to have better personal and emotional skills than male practitioners (Shah \& Ogden, 2006) and patients also report more participatory consultations with female practitioners (Cooper-Patrick et al., 1999).

Patients also show a preference for practitioners from their own ethnic background (Ahmad et al., 2002; Bichsel \& Mallinckrodt, 2001; Kapphahn et al., 1999; Saha, Taggart, Komaromy, \& Bindman, 2000). This may influence patient-practitioner communication (Ahmad, Kernohan, \& Baker, 1989) and promotes patient feelings of participation in the consultation (Cooper-Patrick et al., 1999; see also van Ryn \& Burke, 2000). Patients however seem more accepting of practitioners from ethnic groups other than their own, especially if the practitioner displays a positive personal manner (Gerbert et al., 2003; Shah \& Ogden, 2006).

Professionals' amount of experience is obviously an important factor. This is usually expressed by considering the age of the professional but the results of studies are more equivocal. Some studies suggest that practitioner age does not influence patient preferences (e.g., Furnham et al., 2006), but other works suggest that patients prefer older practitioners because they are seen as having better interpersonal skills and are more thorough in the consultation compared with younger practitioners (Kite, Deaux, \& Miele, 1991; McKinstry \& Yang, 1994). Some patients perceive younger practitioners as more up-to-date (McKinstry \& Yang, 1994) and as having better technical and explanatory skills (Shah \& Ogden, 2006). There is clearly seen to be a trade-off between experience/knowledge and interpersonal skills.

Some studies have looked at factors like practitioner certification, training location, and experience (Bornstein, Marcus, \& Cassidy, 2000). Patients prefer practitioners with better qualifications and experience, but also that such factors may be more important than demographic factors (Bornstein et al., 2000).

Client Preferences for Accountants

There are various studies on the demographic (sex, age, race) and personality 
correlates of the choice of accountancy as a topic of study and a profession (James \& Hill, 2009; Worthington \& Higgs, 2003). There is also some research on culture differences in the choice of auditor/accountant (Hope, Kang, Thomas, \& Yoo, 2008). Yet there appears to be little or no research on the factors potential individual clients look for in an accountant. Inevitably, as with all professionals, expertise and experience are perhaps the major factors, but given these are taken into consideration, what else do they look for and how are these factors weighted? Because money is still regarded as a taboo among many people (Furnham \& Argyle, 1998), accountant-client rapport is clearly as important as any other professional relationship like medicine.

This study replicates that of Furnham, McClelland and Swami (2012). A sample of British participants completed a questionnaire in which they were asked to rate eight lawyers stratified by nationality (British versus Asian), sex (male versus female), and age (younger vs older). A mixed-design analysis of variance showed that there were main effects of lawyer origin (British preferred over South Asian) but not age or sex. Interactions showed evidence of the "fit" hypothesis found in a number of other, mainly medical, studies. That is people tend to prefer people of their own gender, age and ethnic background.

This study looks at the same three variables using an adapted questionnaire and analysis strategy. It was hypothesised that people would favour: British over Indian-trained (H1); Female over Male (H2) and Older over Younger (H3) accountants.

\section{Method}

\subsection{Participants}

One hundred and thirty-one individuals recruited from the general public in the UK participated in this study. Complete data (complete accountant ratings, participant gender and participant age) were available for 115 participants (63 males, 52 females; age $M=32.78$ years, $S D=11.86$ years). Of the $93.9 \%$ who reported their ethnicity, $80.6 \%$ classified themselves as Caucasian, $12.0 \%$ Afro-Caribbean, 3.7\% Asian and 3.7\% as Other. With respect to educational qualifications (reported by $98.3 \%$ of the sample), $29.2 \%$ had completed secondary/further education and $70.8 \%$ had a higher education qualification $(44.2 \%$ undergraduate degree; $26.6 \%$ postgraduate degree). Finally, in terms of marital status (reported by $98.3 \%$ of the sample), $51.3 \%$ of participants were single, $26.5 \%$ were married, $16.8 \%$ were in a relationship, and $1.8 \%$ were separated/divorced or widowed.

\subsection{Materials and Research Design}

Accountant preferences. To examine preferences for accountants we adapted a scale first used by Furnham and Swami (2009). These were their instructions:

We want you to imagine that you have recently been left a great deal of money (over $£ 2$ million) by a relative you hardly knew. You have been advised to get an 
accountant to help you manage this. There are 8 accountants available to match your assigned needs and you must choose which one you would like to help you with your accounts to be maximally efficient in safe-guarding your money. All are fully trained and experienced in the law and accounting practices of this country, though some have additional overseas experience.

Below are each accountant's details. Please rate each from 1 (absolutely don't want to represent you) to 10 (absolutely would love to represent you). A score of 5 or 6 indicates no strong preference.

They were then presented with a list of eight accountants varying dichotomously on the variables of sex (male vs. female), nationality (British vs. Asian), and experience (moderate vs. great) (e.g., "William Daniels, a 36-year-old man who originally trained in Bristol", or "Sushama Rahman, a 35-year-old woman and first trained in Delhi", (a full list of items is available from the corresponding author). Participants rated each lawyer on a 10-point Likert-type scale (1 = Low preference, $10=$ High preference). In previous work, it has been reported that scales of this type have good psychometric properties (e.g., Furnham et al., 2006).

Demographics. Participants provided their demographic details consisting of sex, age, ethnicity, and marital status.

Ethical approval for this study was obtained from the relevant university ethics committees. The authors directly recruited participants from business meetings. Once participation had been agreed, participants completed a two-page paper-and-pencil questionnaire. All participants took part on a voluntary basis and were not remunerated for participation. Once participants returned their completed questionnaires to the experimenters, they were verbally debriefed.

\section{Results}

Prior to the analysis, a median split was conducted on the ages of the participants. The median age of the younger group $(N=60)$ was 23.5 years (Range $=19$ - 30 years) and for the older group $(N=55)$ it was 40.0 years (Range $=31-70$ years). We then conducted a mixed-design analysis of variance in which participant gender (female vs. male) and age (younger vs. older) were between-participant variables, and the gender (female vs. male), age (younger vs. older) and origin (Britain vs. Indian Subcontinent) of the accountants were within-participant variables.

Neither participant gender, $F<1$, nor participant age, $F(1,111)=2.03, p=$ $0.16, \eta_{p}^{2}=0.02$ were significant, and these variables did not interact, $F<1$. There was a main effect of accountant gender, with female accountants $(M=$ 6.24) being preferred over male accountants $(M=5.85), F(1,111)=9.73, p=$ $0.002, \eta_{p}^{2}=0.08$. There was also a highly significant main effect of accountant origin, with British accountants $(M=6.58)$ being favoured over accountants from the Indian Subcontinent $(M=5.50), F(1,111)=42.88, p<0.001, \eta_{p}^{2}=$ 0.28 . There was no main effect of accountant age, $F<1$, but this variable interacted strongly with the gender of the accountant (see Figure 1$), F(1,111)=$ 


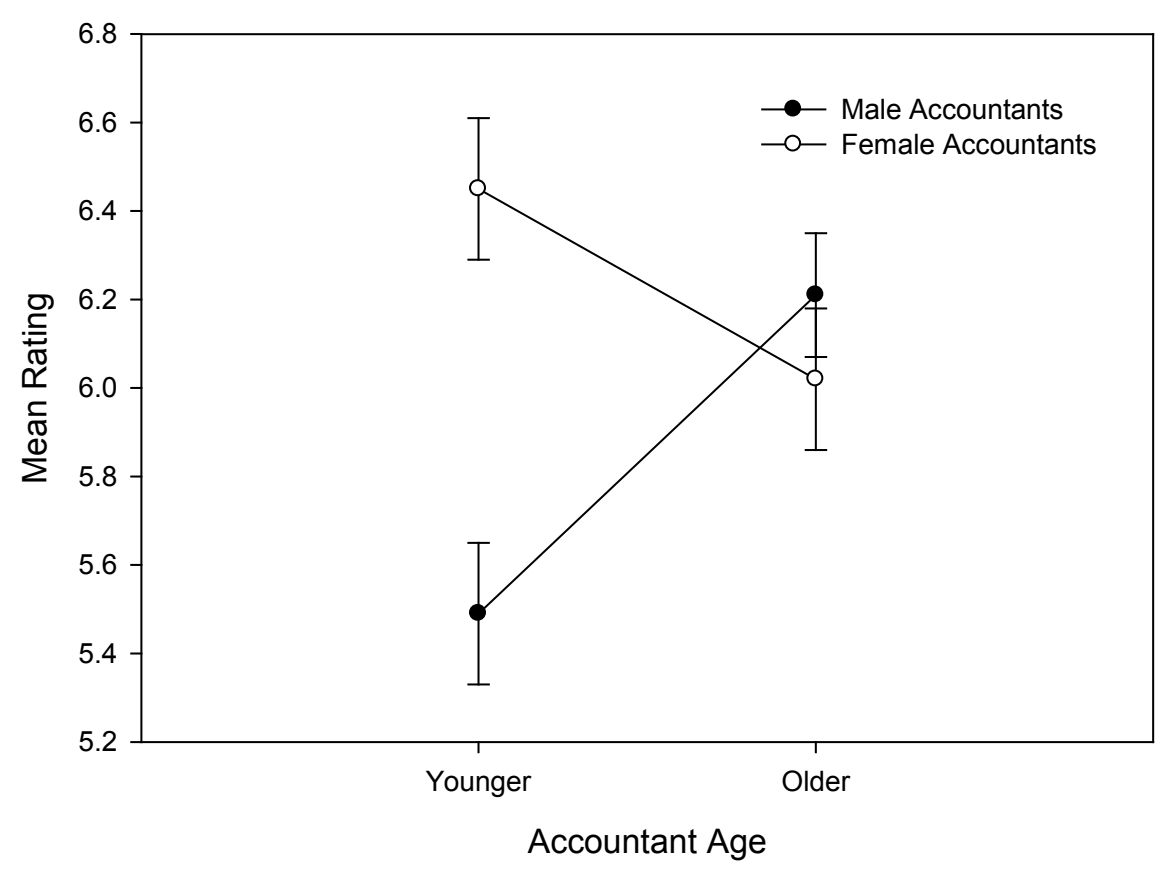

Figure 1. Mean preference ratings as a function of the age and gender of the accountants.

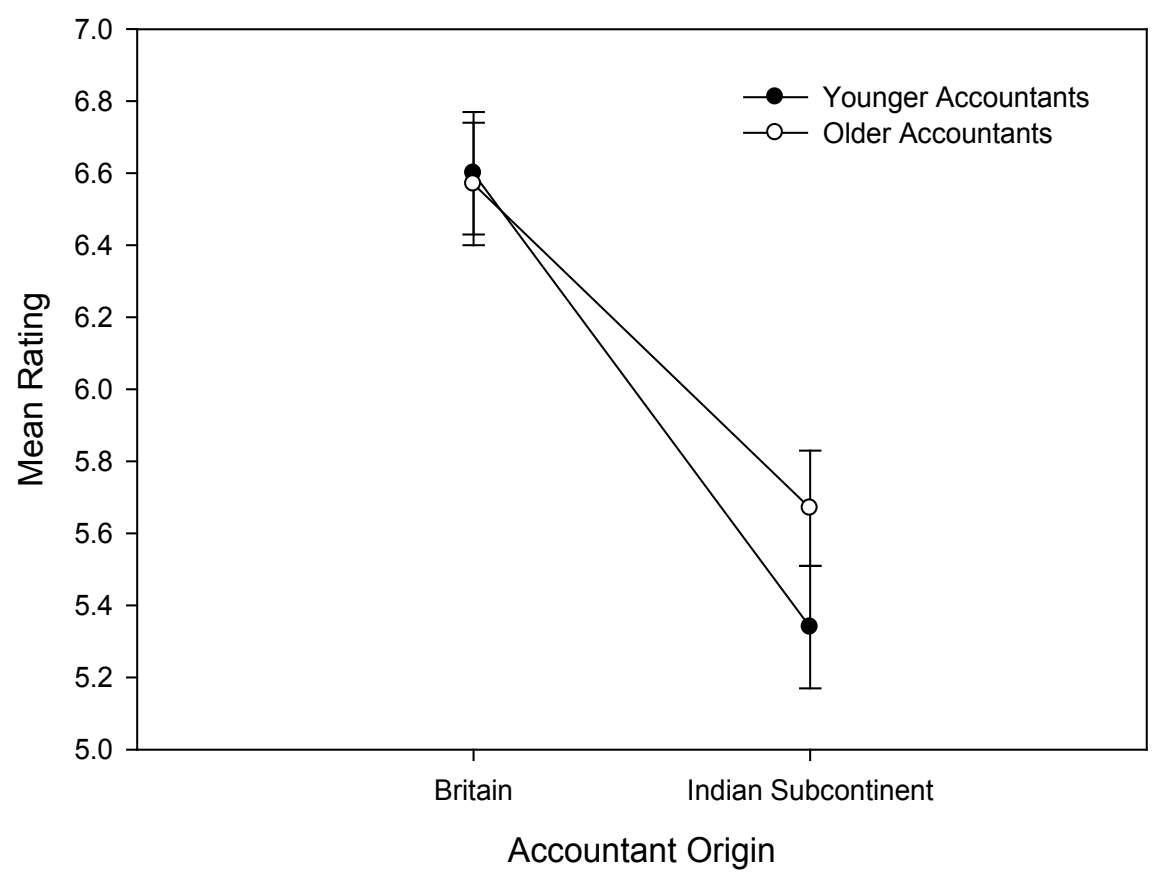

Figure 2. Mean preference ratings as a function of the origin and age of the accountants.

39.54, $p<0.001, \eta_{p}^{2}=0.26$. Simple effects analyses revealed that for younger accountants, females $(M=6.45)$ were preferred over males $(M=5.49), F(1,111)$ $=32.78, p<0.001, \eta_{p}^{2}=0.23$, but there was no gender effect for older accountants (female $M=6.03$; male $M=6.20$ ), $F(1,111)=1.77, p=0.19, \eta_{p}^{2}=0.02$. There was also a weak but significant interaction between the age of the accountant and the background of the accountant (see Figure 2 ), $F(1,111)=4.26$, 
$p=0.041, \eta_{p}^{2}=0.04$. For British accountants, age was not a significant determinant of preference (younger $M=6.60$; older $M=6.57$ ), $F<1$, but for accountants trained in the Indian Subcontinent older accountants $(M=5.67)$ were preferred to younger accountants $(M=5.34), F(1,111)=4.01, p=0.048, \eta_{p}^{2}=$ 0.04 .

There were two significant three-way interactions. The first was an interaction between the age of the participants, and the background and the gender of the accountants, $F(1,111)=4.37, p=0.039, \eta_{p}^{2}=0.04$ (see Figure 3 ). For younger participants (Figure 3 upper panel) there was a significant interaction between the background and the gender of the accountants, $F(1,58)=8.39, p=0.005$, $\eta_{p}^{2}=0.13$. Simple effects analysis revealed that there was no gender preference for British accountants (female $M=6.74$; male $M=6.86$ ), $F<1$, but for accountants from the Indian Subcontinent, females $(M=5.85)$ were preferred over males $(M=5.32), F(1,58)=5.40, p=0.024, \eta_{p}^{2}=0.09$. In contrast, amongst older participants (Figure 3 lower panel) there was no interaction between the background and the gender of the accountants, $F<1$. The second was an interaction between the age of the participants, the background of the accountants and the age of the accountants, $F(1,111)=7.55, p=0.007, \eta_{p}^{2}=0.06$ (see Figure 4 ). For the younger participants (Figure 4 upper panel) there was an interaction between the background and the age of the accountants, $F(1,58)=9.64, p$ $=0.003, \eta_{p}^{2}=0.14$. Simple effects analysis showed that there was no age preference for British accountants (younger $M=6.90$; older $M=6.69$ ), $F<1$, but for accountants from the Indian Subcontinent, older accountants $(M=5.91)$ were preferred over younger accountants $(M=5.27), F(1,58)=6.22, p=0.016, \eta_{p}^{2}=$ 0.10 . For the older participants (Figure 4 lower panel) the interaction between the background and age of the accountants was not significant, $F<1$.

Thus the results showed that participants preferred female accountants from their own country.

\section{Discussion}

All professionals recognise the importance of client skills and rapport to establish and maintain good and long-lasting relationships. In any competitive business, these issues are of utmost importance, after ensuring that the staff are well trained and experienced. Accountancy, law and medicine share many things in common including the importance of professional-client communication and trust.

This study showed as previous research in this series concerned with choice of counsellor, dentist, doctor and lawyer that people prefer those of their own ethnicity/trained in their own country (Furnham \& Swami, 2008, 2009; Furnham, Petrides, \& Temple, 2006; Furnham, McClelland, \& Swami, 2012). There may be many reasons for this preference including possible racism but also the belief that communication will be easier or that "foreign" training is not as good or as relevant as training "at home". Whereas medicine and medical practices do not differ greatly between countries, there are many differences in legal systems and 


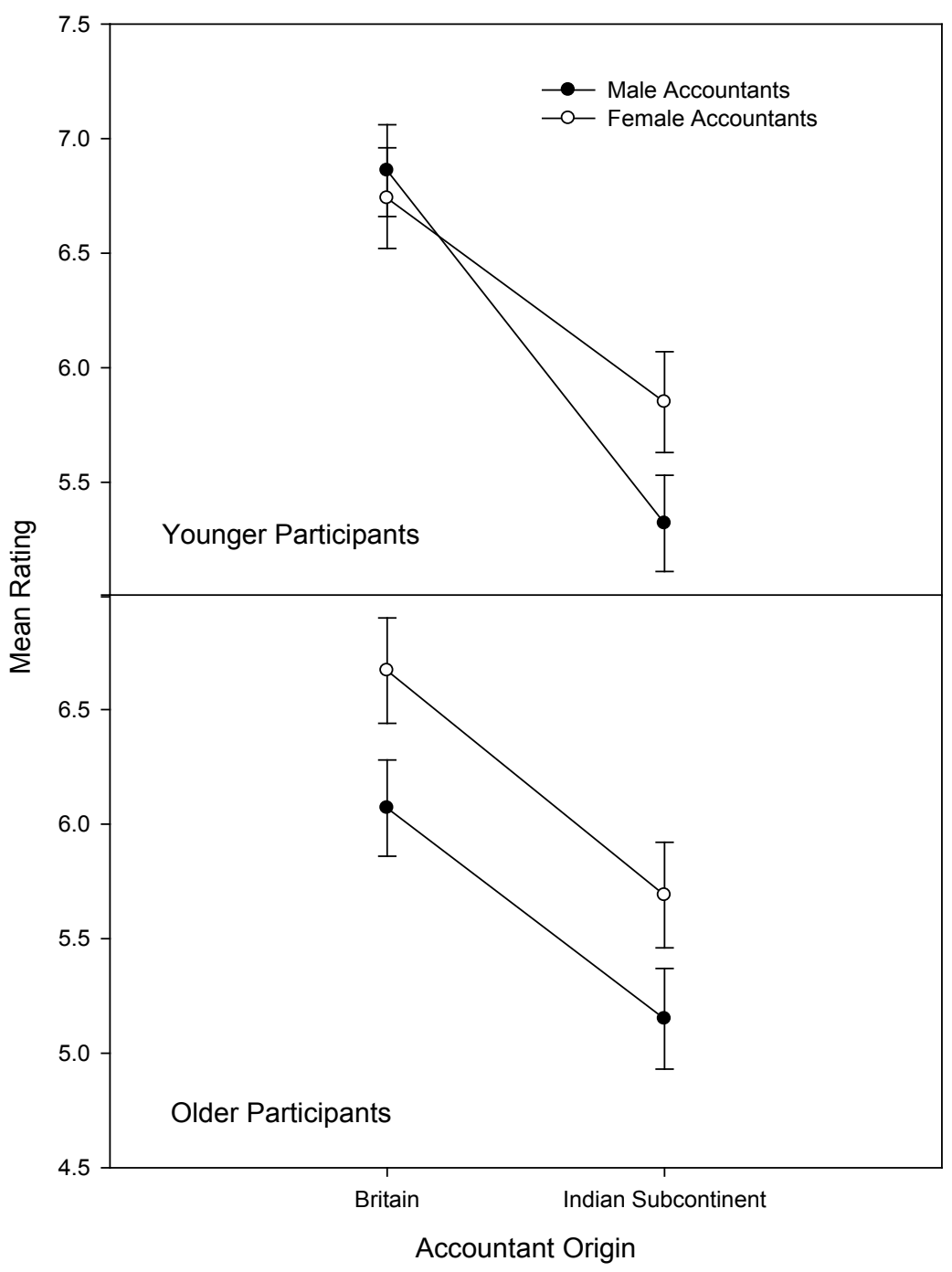

Figure 3. Mean preference ratings as a function of the age of the participants, and the origin and gender of the accountants.

also accountancy though things may be changing through internationalisation.

There was evidence in this study of a preference for female over male accountants, though there was no participant gender difference: that is, both males and females showed a preference for a female accountant. Though the study cannot indicate why this is the case, it is possible to speculate. It is possible that females are thought of as more thorough or accurate in their work. Equally, it may be that they are thought to be more emotionally intelligent and easier to communicate with (Furnham, 2008).

In this study, there was no significant main effect for age, possibly because of the age range. Had we suggested the accountants were in their 20s (and therefore very recently qualified) or in their sixties (and near retirement), there may have been a significant difference. Interactions suggested that among the younger accountants, females are preferred though it is unclear why this is the case. There 


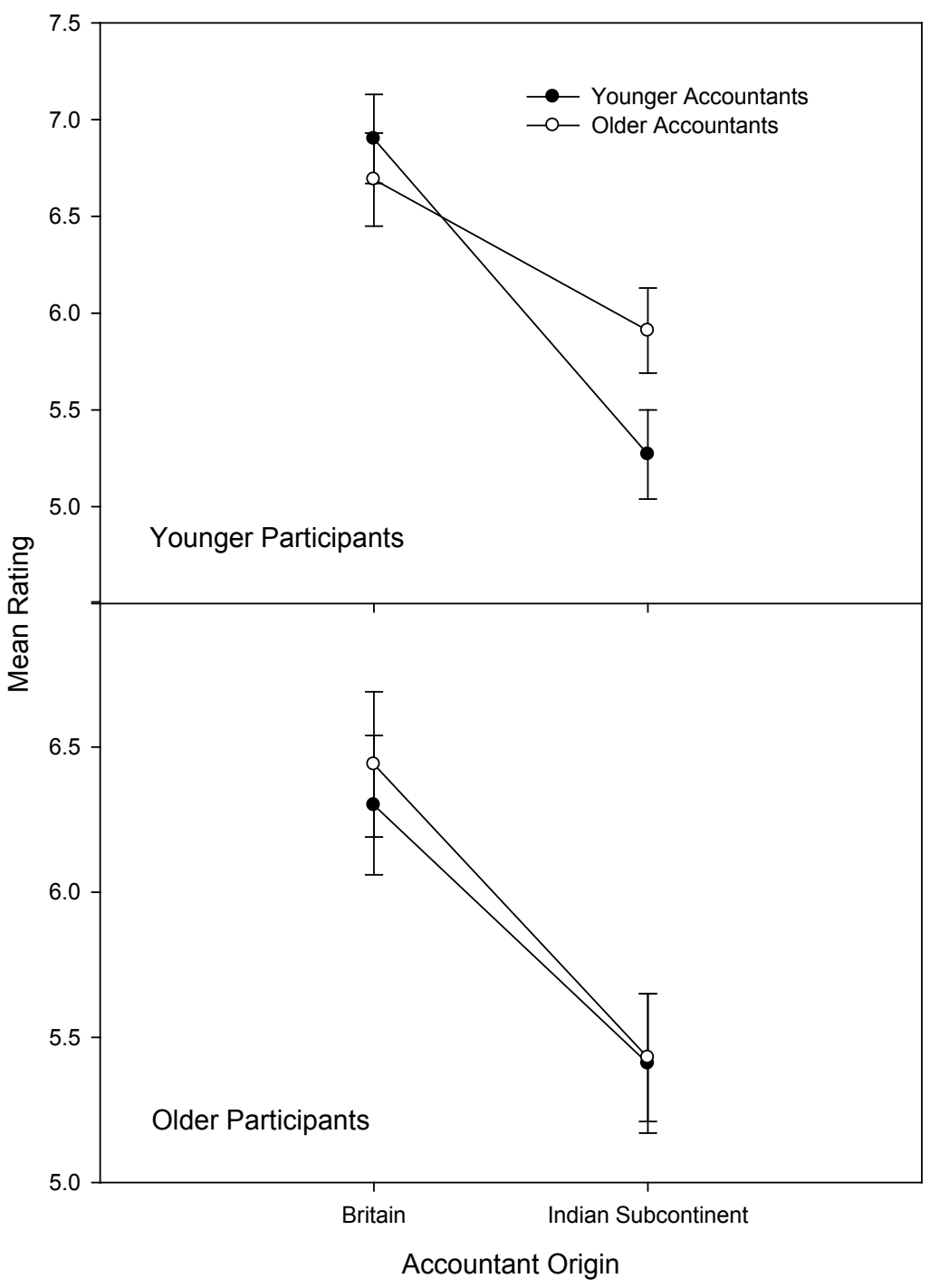

Figure 4. Mean preference ratings as a function of the age of the participants, and the origin and age of the accountants.

was also an age $\mathrm{x}$ ethnicity interaction which showed people preferred older "foreign" accountants to younger ones, perhaps because it was thought that they had spent more time abroad and able to learn the language, processes and procedures better.

This study had, inevitably, certain limitations. This study concentrated on only a very limited number of factors concerning accountants. We did not consider their personality, social skills, attractiveness, fees, reputation and access all of which are important, possibly even more important than the factors we investigated (Furnham, McClelland, \& Swami, 2012). Next, we had a relatively small and unrepresentative sample. Nor did we get evidence of their personal experience of accountants in any capacity. Nevertheless, we believe this pilot study may serve as an impetus to further research into the determinants of personal preferences for accountants. 


\section{Conflicts of Interest}

The authors declare no conflicts of interest regarding the publication of this paper.

\section{References}

Ahmad, F., Hansa, G., Rawlins, J., \& Stewart, D. E. (2002). Preferences for Gender of Family Physician among Canadian-European Descent and South-Asian Immigrant Women. Family Practice, 19, 146-153. https://doi.org/10.1093/fampra/19.2.146

Ahmad, W. I. U., Kernohan, E. E. M., \& Baker, M. R. (1989). Patients' Choice of General Practitioner: Influence of Patients' Fluency in English and the Ethnicity and Sex of the Doctor. Journal of the Royal College of General Practitioners, 39, 153-155.

Bichsel, R. J., \& Mallinckrodt, B. (2001). Cultural Commitment and the Counseling Preferences and Counselor Perceptions of Native American Women. The Counseling Psychologist, 29, 858-881. https://doi.org/10.1177/0011000001296007

Bornstein, B. H., Marcus, D., \& Cassidy, W. (2000). Choosing a Doctor: An Exploratory Study of Factors Influencing Patients' Choice of a Primary Care Doctor. Journal of Evaluation in Clinical Practice, 6, 255-262. https://doi.org/10.1046/j.1365-2753.2000.00256.x

Brink-Muinen, A. V. C., Bakker, D. H. D., \& Bensing, J. M. (1994). Consultations for Women's Health Problems: Factors Influencing Women's Choice of Sex of General Practitioner. British Journal of General Practitioners, 44, 205-210.

Cooper-Patrick, L., Gallo, J. J., Gonzales, J. J., Thi Vu, H., Powe, N. R., Nelson, C., \& Ford, D. E. (1999). Race, Gender, and Partnership in the Patient-Physician Relationship. Journal of the American Medical Association, 282, 583-589.

https://doi.org/10.1001/jama.282.6.583

Derose, K. P., Hays, R. D., McCaffrey, D. F., \& Baker, D. W. (2001). Does Physician Gender Affect Satisfaction of Men and Women Visiting the Emergency Department? Journal of General Internal Medicine, 16, 218-226. https://doi.org/10.1046/j.1525-1497.2001.016004218.x

Elstad, J. I. (1994). Women's Priorities Regarding Physician Behaviour and Their Preference for a Female Physician. Women and Health, 21, 1-19. https://doi.org/10.1300/J013v21n04_01

Furnham, A. (2008). Personality and Intelligence at Work. London: Routledge. https://doi.org/10.4324/9780203938911

Furnham, A., \& Argyle, M. (1998). The Psychology of Money. London: Routledge.

Furnham, A., McClelland, A., \& Swami, V. (2012). The Influence of Person Traits on Lawyer Selection among British Adults. Journal of General Psychology, 139, 217-229. https://doi.org/10.1080/00221309.2012.693974

Furnham, A., Petrides, K. V., \& Temple, J. (2006). Patient Preferences for Medical Doctors. British Journal of Health Psychology, 11, 439-449. https://doi.org/10.1348/135910705X67529

Furnham, A., \& Swami, V. (2008). Patient Preferences for Psychological Counsellors: Evidence of a Similarity Effect. Counselling Psychology Quarterly, 21, 361-370. https://doi.org/10.1080/09515070802602146

Furnham, A., \& Swami, V. (2009). Patient Preferences for Dentists. Psychology, Health and Medicine, 14, 143-149. https://doi.org/10.1080/13548500802282690

Gerbert, B., Berg-Smith, S., Mancuso, M., Caspers, N., Danley, D., Herzig, K. et al. (2003). 
Video Study of Physician Selection: Preferences in the Face of Diversity. Journal of Family Practice, 52, 552-559.

Hope, O.-K., Kang, T., Thomas, W., \& Yoo, Y. (2008). Culture and Auditor Choice. Journal of Accountancy and Public Policy, 27, 357-373. https://doi.org/10.1016/j.jaccpubpol.2008.07.003

James, K., \& Hill, C. (2009). Race and the Development of Career Interest in Accounting. Journal of Accountancy Education, 27, 210-222. https://doi.org/10.1016/j.jaccedu.2010.07.005

Kapphahn, C. J., Wilson, K. M., \& Klein, J. D. (1999). Adolescent Girls' and Boys' Preferences for Provider Gender and Confidentiality in Their Health Care. Journal of Adolescent Health, 25, 131-142. https://doi.org/10.1016/S1054-139X(99)00050-6

Kerssens, J. J., Bensing, J. M., \& Abdela, M. G. (1997). Patient Preference for Genders of Health Professionals. Social Science and Medicine, 44, 1531-1540. https://doi.org/10.1016/S0277-9536(96)00272-9

Kite, M. E., Deaux, K., \& Miele, M. (1991). Stereotypes of Young and Old: Does Age Outweigh Gender? Psychology of Ageing, 6, 19-27. https://doi.org/10.1037//0882-7974.6.1.19

McKinstry, B., \& Yang, S. Y. (1994). Do Patients Care about the Age of Their General Practitioner? A Questionnaire Survey in Five Practices. British Journal of General Practice, 44, 349-351.

Plunkett, B. A., Kohli, P., \& Milad, M. P. (2002). The Importance of Physician Gender in the Selection of an Obstetrician or a Gynaecologist. American Journal of Obstetrics and Gynaecology, 185, 926-928. https://doi.org/10.1067/mob.2002.123401

Saha, S., Taggart, S. H., Komaromy, M., \& Bindman, A. B. (2000). Do Patients Choose Physicians of Their Own Race? Health Affairs, 19, 76-83. https://doi.org/10.1377/hlthaff.19.4.76

Shah, R., \& Ogden, J. (2006). "What's in a Face?" The Role Doctor Ethnicity, Age, and Gender in the Formation of Patients' Judgements: An Experimental Study. Patient Education and Counseling, 60, 136-141. https://doi.org/10.1016/j.pec.2004.12.005

Short, D. (1993). First Impressions. British Journal of Hospital Medicine, 50, 270-271.

Swami, V., McClelland, A., Bedi, R., \& Furnham, A. (2011). The Influence of Practitioner Nationality, Experience and Sex in Shaping Patient Preferences for Dentists. International Dental Journal, 61, 193-198. https://doi.org/10.1111/j.1875-595X.2011.00056.x

van Ryn, M., \& Burke, J. (2000). The Effect of Patient Race and Socioeconomic Status on Physicians' Perceptions of Patients. Social Science and Medicine, 50, 813-828. https://doi.org/10.1016/S0277-9536(99)00338-X

Worthington, A., \& Higgs, H. (2003). Factors Explaining the Choice of Finance Major. Accounting Education, 12, 1-21. https://doi.org/10.1080/0963928032000088831

Young, J. W. (1979). Symptom Disclosure to Male and Female Physicians: Effects of Sex, Physical Attractiveness and Symptom Type. Journal of Behavioural Medicine, 2, 159-169. https://doi.org/10.1007/BF00846664 